\title{
Plato Meets Lawnmower Man in the Virtual Polis: The Case of PS $\mathbf{7 7 6}$
}

\author{
Ernest J. Yanarella, University of Kentucky
}

If popular movies are signposts of mass cultural fantasies, political terrors, and psychic nightmares, we Americans are in for some tough sledding as we negotiate the pathway to the next millennium. Already, we are being bombarded by cruel anticipations of ecological collapse, technophilic hopes of planetary domination and terra/terror forming, and hallucinogenic plans for disembodied consciousnesses streaming through the vast and placeless void of cyberspace. In this cultural ethos, technological optimism and social pessimism run rampant while reasoned political hope is in short supply.

Speculating on the possible destiny of the city and true urbanity in the last half of the twentieth century, historian Lewis Mumford was moved to ask: "Will the city disappear or will the whole planet turn into a vast urban hive? Can the needs and desires that have impelled men to live in cities recover, at a still higher level, all that Jerusalem, Athens, or Florence once seemed to promise? Is there still a living choice between Utopia and Necropolis: the possibility of building a new kind of city that will, freed of inner contradictions, positively enrich and further human development?" (Mumford 1961, 3; emphasis added).

\section{Course Overview}

Guided by the hopeful spirit of Mumford's stark question, I offered in the spring of 1996 and again in

Ernest J. Yanarella is a professor of political science and the associate director of the Center for Sustainable Cities at the University of Kentucky. His primary teaching and research interests are policy studies and political theory. Recent research grants have involved him in issues of political economy, labor, and sustainable cities. $\mathrm{He}$ is collaborating on a computerized learning game tentatively titled "Emerald City: The Sustainability Game."
1998 (with Dick Levine) a graduate seminar on sustainable urban design seeking to utilize the possibilities afforded by the Internet and its myriad and seemingly choatic resources. (See the seminar web site at www.uky.edu/Classes/PS776/.) Combining an effort to present the historical sweep and social development of the city from antiquity to the present with focused concern with designing and building sustainable cities of the future, PS 776, "Sustainable Urban Design," was designed to provide a forum for revisiting the hopes and dreams (as well as nightmares) of urban existence. It was also intended to allow students to chart out a path for recuperating those elements of urbanity, civility, human scale, daily social intercourse, and sense of place and identity characterizing the highest values and wishes of human collectivities seeking to constitute a built environment fit for human habitation at peace with nature.

The seminar was also focused on the utopian possibilities inscribed in the planning visions, architectural designs, religious testaments, and political ambitions of urban projects scattered across the globe. Beginning with historical, urban-architectural, and cultural cues to good city form, the seminar was designed to introduce students to both the formal and substantive features of sustainable urban design drawn from the traditions of medieval urban planning, the garden city and new towns movement, and the organic town and communitarian planning of Ebenezer Howard, Patrick Geddes, Lewis Mumford, Paul Goodman, and others. Particularly important in mobilizing student awareness of the origins of the city were Mumford's speculations on the urban center's beginnings in prehistory.

In The City in History, Mumford forcefully argued that "the city of the dead is the forerunner, almost the core, of every living city" (1961, 7). As he intuited, the living city begins in the Paleolithic shrines and burial places, which provide the first traces of social gathering and civic life for prehistoric nomadic peoples. Likewise, these ancient burial places prefigure the linking of future cities as tokens of secular and technological power to transcendental and religious underpinnings. Lurking in the background of this theory of the origins of the city of the living in the city of the dead, however, is the fear that Necropolis, not Utopia, may yet be the fate of urban evolution. If this nightmare is not to be fulfilled, then the organic, life-enhancing elements Mumford associated with the Neolithic village (and similar expressions developed by Howard, Geddes, and Goodman) would have to be revived in a new project for overcoming the advance of the ancient "megamachine" in modern dress and for surpassing the anti-urban visions of Frank Lloyd Wright, LeCorbusier, and others.

In the seminar, that new project of urban design in the dawning new millennium-a strategy for sustainable cities--was built upon the manifesto, founding principles, and research, teaching, and design agenda of the University of Kentucky's Center for Sustainable Cities (Yanarella and Levine 1992a, 1992b). ${ }^{1}$

Grounded in the democratic heritage of the Western political tradition and animated by the social and technological possibilities of late modernity pacified by an emerging global ecological consciousness, the Center has striven to combine theoretical vision, urban-architectural design, and strategies of implementation into an intellectual forum for demonstrating both the feasibility and necessity of building future sustainable cities as the best and only hope for avoiding the descent into Necropolis that so plagued Mumford in his later years. 


\section{Multimedia and Computer Seminar Resources: Ancient Cities, Imaginary Cities, and Sim Cities}

One of the many innovative features of this seminar lay in its being taught in one of three "smart classrooms" underwritten by the College of Arts and Sciences. Housed on the third floor of White Hall on the UK campus, the classroom was equipped with an LCD projector hooked up to a PowerMac computer, which allowed computer files, Powerpoint presentations, CD-ROMs, and the web to be projected onto a viewing screen, and an electronic overhead. This technology permitted photographs, graphics, and assorted text material to be viewed on the front screen.

The new classroom setting afforded many opportunities to use new multimedia teaching resources. In the first iteration of the seminar, I used Scientific American's CDROM, "Exploring Ancient Cities" (published by Sumeria, Inc.). In showing students the portion of this CD-ROM focusing on Teotihuacan, the first city in the Americas, my purpose was to provide a visual medium for the students to appreciate some of Mumford's points about the origins of the city, the metaphors of the city as magnet and container, and the organization of public, commercial, and private space in this relatively densely populated urban setting. This CD-ROM, though informative in some respects, demonstrated how not to take advantage of this new multimedia pedagogical tool. "Exploring Ancient Cities" fostered too much conventional notetaking and too little appreciation of the photographic and artistic images and provided little or no opportunity for viewer interaction with the information or visuals of the site.

By contrast, "The Ultimate Frank Lloyd Wright" (Byron Preiss Multimedia), which I used the second time I taught PS 776, very nearly realized the potential of this new medium. The production and content of this CD-ROM avoided the proclivity of educational resource developers to squander 650 megabytes of space to translate complex and potentially exciting topics into highly conventional and tedious voice-over lectures accentuating textual content over multimedia presentation. Packed into this single CD-ROM was an integrated biographical sketch of Wright's life punctuated by short film clips of him, a series of architectural walkthroughs of some of his most famous houses, a library of structural elements comprising Wright's distinctive architectural style, and a modeler allowing the student to design a Frank Lloyd Wright-type building from those basic structural elements. In sum, "The Ultimate Frank Lloyd Wright" offered intellectual engagement, close viewing, active learning, and keen appreciation for the simple elegance of this modernist master builder and his organic architecture. It also served as an invaluable bridge to the seminar's concern with Wright's grave shortcomings as an urban architect and planner (his preference for the individual house over urban fabric, the anti-political bias of his simplistic pastoralism, and his mistaken belief in the positive revolutionary impact of the automobile on the built environment).

From these contrasting experiences, I concluded that a first-rate CD-ROM must include, at a minimum, (1) prodigious information creatively presented in multiple media formats and venues (incorporating panoramic navigation of sites, AVIs or QuickTime movies, simple modeling, and the easy translation of textual or numerical information into charts, tables, or other graphics); (2) an inviting and commonsensical opening user interface (allowing student and teacher to negotiate the CD-ROM's multimedia presentations and formats easily and with a minimum of effort or confusion); (3) strong and intuitive interactive features (providing links within files, documents, and entries and incorporating pedagogical activities allowing the student to test out or examine ideas and concepts); and (4) aesthetically attractive presentation (resisting both the Scientific American-Encyclopedia Britannica proclivity noted above and Microsoft Encarta's past pro- pensities toward offering glitter and glitz over content and depth).

Another method used to trigger curiosity and expand imagination among the enrolled students was adoption of Italian surrealist writer Italo Calvino's novel, Invisible Cities (1972). Perhaps Calvino's most ambitious work, this novel is a loosely connected series of vignettes or short treatments of metaphorical cities supposedly encountered by Marco Polo in his travels around the world at the behest of Kublai Kahn at the sunset of his life.

For the purposes of the seminar, the novel was an invitation to students to grapple with the metaphorical meaning of half a dozen or so city narratives assigned from the novel. Students were encouraged to reflect on how one or another of the cities highlights the utopian or dystopian possibilities underlying the history, trajectories, and hopes of the City as haven, work of art, home of humankind, necropolis, prison, token of technology and power, ornament, etc. Noting that readerly interpretation is hegemonic in Invisible Cities, the seminar teased out instructive answers to these and other questions.

Among the nine cities discussed in the seminar, several stand out for the lessons they offer to the enterprise of building sustainable cities of the future. In the context of the seminar, the story of Fedora (3233 ), the City of the Museum of Models, issues a warning to urban planners and model builders that plans and models must be continually linked to the real city and not become mere objects of the struggle for conceptual perfection unconnected to the political means for realizing the dreams and visions informing those idealized plans and models.

Calvino's Theodora (159-60), the Humanist City, offers chastening advice to those imbued with the "arrogance of humanism" (Ehrenfeld 1981). Beginning with one pest, Theodora's citizens find that they must exterminate each succeeding predator and prey until all animal species are gone. Humanist to the core, city residents imagine themselves the high point of civilization 
and Theodora the culmination of humankind's conquest of nature and its other entire species. In truth, the citizens have forgotten that the human body and brain are the evolutionary achievements of nature and that, as such, they store within them traces of their evolutionary rise in out-of-the-way recesses of the mind or some vestigial organ. Theodorans' unconscious minds remember, however, and the "lower" species return in mythical form to haunt and repossess the city, awakening ancient terrors and troubling the sleep of the city's dwellers.

Octavia and Andria portray more hopeful emblems of reconciliation and ecological care. Octavia (Calvino 1972, 75), the Spider-Web City, may be taken to symbolize the Ecological City. In a city suspended by a web-like network of ropes between two cliffs, the inhabitants of Octavia approach the city's fragility both as a threat to human life and its very sustenance. Its citizens cling to the web, for Octavia is both their "passage" and their "support." Happier and more secure than occupants of other cities, Octavians do not dream dreams of immortality, perfection, and all the other fantastic conceits of modernity's terrors. Instead, they clutch to each other for all the days they have, living within nature and its limitations.

Andria (150-51), the City of the Cosmos, is celestial, its every change perfectly attuned to the movement of the stars and constellations. Like the ancient Mayans, its inhabitants are cosmological planners, assuring themselves beforehand that every innovation in the city is weighed in terms of the ecological costs and benefits to themselves, their city, and the cosmos. Because they have learned to place human needs and social change within a larger ecological framework of which humankind is a small part, theirs is a cosmoscentered, not a human-centered, city.

In the seminar, stimulation of the human imagination through fiction gave way to discussing virtual communities, visiting telematic cities, and engaging urban simulation and gaming. Eschewing top-down, technocratic approaches to the design and building of future sustainable communities, the course placed at the center of discussion and debate the promise and perils of digital communities in cyberspace. Moreover, since, as Hannah Arendt (1958) and others have emphasized, genuine political action has historically been associated with embodied citizens engaging in face-to-face dialogue and debate in a public place, the implications of the virtual polis (where "netizens" meet in electronic space) for democratic politics was opened up for debate.

The model and touchstone of virtual communities is Blacksburg, Virginia, the most well-known of electronic villages. In one meeting, the participants viewed a documentary on the Blacksburg virtual community and then visited its web site (www.bev.net). Much discussion and critical commentary was offered in seminar on the tendencies of these digital communities to veer from their democratic potential of becoming virtual polises populated by netizens in cyberspace into commercial electronic shopping malls and advertising boards with only residues of a cybernetic public sphere (see Poster 1995).

The promise of urban modeling as a tool for enhancing democratic policy making and urban planning was explored through intense seminar discussion over the scope and limits of Maxis' "SimCity 2000." Working from Paul Starr's (1994) keen observations on the "seductions of sim[ulation]" in policy making, the seminar participants dissected the operating assumptions of the edutainment game, weighing its public education potential against its commercial and entertainment elements and values. They also deconstructed the implicit model of good city development structured into its biases and gameplay-a model openly characterized as a "capitalist land use ecology" game (cited in Starr 1994, 24). Especially provocative was Julian Bleeker's critical analysis of the displacement of issues of race and racism in the modern city in SimCity 2000 through their "absent presence" in the game-that is, the explicit absence of racial tensions and racial markers and their lurking presence in the monsters ("Nessie") and disasters (fires, tornadoes, etc.) that periodically and unexpectedly erupt in the simulated city (Bleeker 1995). An important point of these exercises was to encourage students to confront tensions and ambiguities afforded by virtual communities and urban simulation in the struggle to enlarge the public arena and foster wider public participation in building and governing cities.

\section{Engaging the Sustainable Cities Agenda: Student Hyptertext Projects}

Graduate students undertook two seminar projects using computer, multimedia, and 3D modeling techniques-a modest hypertext project focusing on one urban or anti-urban visionary and a semester-long team project showcasing one of a halfdozen major urban sustainability programs throughout the United States. The intent of the two hypertext assignments was to familiarize students with a subject matter convergent with the strategy and agenda of sustainable cities and to introduce them to an emergent computermediated communication (CMC) method of preparing and distributing such CMC texts on the Internet.

In the first hypertext project, students in the spring 1996 course chose precursors or antagonists of sustainable cities including the Scottish biologist-urbanist Patrick Geddes, the social ecologist and urban anarchist Murray Bookchin, the British urban visionary Ebenezer Howard, the anti-modern philosopher Ivan Illich, and the contemporary urban-architectural theorist Richard Sennett. This past spring, students explored the relevance of urban historian Lewis Mumford, French modernist urban designer LeCorbusier, and French urbanist Tony Garnier, among others. All the projects proved instructive of the way that diverse intellectual traditions and disciplines have cultivated ideas of the city as the home of humankind reaching back to moments of high urban attainment (the Greek city-states, medieval cities) 
and periods of profound pastoral attraction (the bucolic idylls of Hesiod and Virgil).

The second hypertext assignment was designed as a semester-long project engaged by individuals or teams. In the 1996 seminar, two pairs of students undertook team projects. One team focused on the background and prospects for Lexington, Kentucky, being transformed into a sustainable city. The other undertook a critical exploration of Chattanooga, Tennessee, the United States' most well-known and publicized sustainable city program. Taking on the alleged "crown jewel" of American sustainable community programs, these students illustrated the extent to which the foundations of the activity have been strongly shaped by corporate values and technocratic goals that have effectively marginalized the interests of both Chattanooga's large black population and its Native American minority. These students were able to develop this trenchant critique from materials drawn predominantly from web sites maintained by those whose voices were silenced in the vision forums or excluded from the planning platforms of Sustainable Chattanooga. Other students took an individual approach to completing this longer project, focusing on topics like the state of the development of sustainability indicators in selected sustainable community programs throughout North America, and the failed promise of a HUD-supported sustainable community initiative in Richmond.

Along with the course seminar and web links gathered by the instructor, the student-prepared hypertexts were uploaded onto the seminar's web site. Indicative of the widespread dissemination and influence of these short and long hypertexts is the email traffic they have generated and the impact they have had on public commentary on sustainable communities. For example, the hypertext on Patrick Geddes elicited an exchange between the archivist of the Geddes papers in Edinburgh, Scotland, and myself, which led to publication of a short hypertext on Geddes' Outlook Tower (www.ed.ac.uk/ cce/geddes/ ernie.htm). Shortly thereafter, the nephew of Patrick Geddes contacted me upon seeing the student hypertext, revealing that he had in his possession many original writings of his uncle with no idea what to do with them. I immediately contacted the Geddes' archivist, who successfully negotiated the donation of those papers to the University of Edinburgh's library. In another case, the critical perspectives of the Sustainable Chattanooga hypertext were incorporated as the only critical comments into a National Public Radio series on Sustainable Chattanooga.

Finally, last summer (1997), as a result of visiting the seminar web site, former governor of California Jerry Brown commissioned members of the Center for Sustainable Cities and former seminar participants to prepare an outline sustainable cities plan for Oakland, California. Called "Oakland Ecopolis" (1997), this plan for a green plan was put on Brown's web site. When he declared his candidacy last fall for the Oakland mayoral post, the proposed plan received much media coverage and political commentary.

\section{Conclusion}

Latter-day students and close observers of the cyberspace, from urban architect William Mitchell (1995) to literary theorist Scott Bukatman (1993), have pointed out the startling similarities between patterns of the modern megalopolis and the design of the computer chip. These affinities have important social implications for the emerging multidimensional, increasingly telematic, city. As a quiet, largely unacknowledged revolution in modern mass telecommunications fostering the partial etherialization of the geo-physical city takes place
(Graham and Marvin 1996), one question that arises is, "How can these inchoate 'soft cities' unfolding before and around us and the "hard cities' of our past be integrated and democratically controlled?"

As a seminar on public policy and democratic theory, PS 776 is intended to sensitize graduate students to the stakes in the continuing battle over cyberspace as public space and as commercial space. Eschewing a "onedimensional" analysis of its authoritarian possibilities, the seminar was designed, in part, to

express a democratic political agenda convergent with the Center's agenda for sustainable cities. As such, the course was supposed to help students avoid the tendencies of cyberpunk fiction writers to polarize physical space and electronic space, the human body and consciousness, and to conger up the mythical aspiration stemming from Cartesianism to shuck human consciousness from its bodily anchorage (i.e., the body as dispensable "meat puppet") and upload the electronic impulses of human consciousness onto the net and into cyberspace where the modernist wish-dream of immorality might be realized.

Consider a scene in the 1992 film, "The Lawnmower Man." The mentally-challenged gardener cum artificially-enhanced genius Jobe straps himself and his young friend Austin into sled-like contraptions attached to a high-speed computer. In prone position, they race through a Nintendo-like cyber-course as their focal consciousness is projected onto robot avatars that propel them through the winding metallic tubes and closing jagged doors. Ironically, as the camera shifts between their cyber "selves" in virtual reality and their bodily being in the room, their bodily movements on the sleds in physical space through which their cyberspace actions are directed give 
lie to the idea that their consciousness can be separated from their body as homunculus.

As a looming political challenge of enormous proportions, cyberspace then is not an alternative to human habitation on the earth, but merely another form of habitation within a more encompassing built environment enclosed within an even more encompassing set of relations in nature. As the approach of a new millennium provokes profound cultural anxiety about the shape of things to come, the democratic challenge of an emergent new medium for social and political discourse is to reconnect our democratic hopes and dreams and our embodied existence in virtual space and terra firma. In other words, the gauntlet hurled at the feet of those advancing an agenda for sustainable cities is to find the means to negotiate these complex-woven relationships among cyberspace, built environment, and nature and build the true sustainable city of the future in alliance with the democratic potential of emergent technology and the virtual polis.

\section{Notes}

1. Although "sustainability" and its more familiar derivative, "sustainable development," have become watchwords in global forums and conferences, and rallying cries for social movements and NGOs, they are perhaps best understood as "essentially contested concepts" that conceal as much as they reveal. As a result, we sought to overcome prevailing conceptual confusion over these terms by laying out the essential lines of argument developed in greater detail in several key publications and papers of the Center (Levine and Radmard 1992; Yanarella and Levine 1992a, 1992b; Levine and Yanarella 1994).

The most commonly accepted-and minimalist-definition of sustainability is the one offered in the Brundtland Commission report: development that "meets the needs of the present without compromising the ability of future generations to meet their own needs" (United Nations 1987). Going beyond this minimalist stance, we draw upon the distinc- tion between growth and development offered by Daly and Cobb $(1989,71)$, who define "growth" as "quantitative expansions in the scale of the physical dimensions of the economic system," while defining "development" as "qualitative change of a physically nongrowing economic system in dynamic equilibrium with the environment." The image of ecological sustainability offered by Michae Redclift, we then argue, may be taken as an essential point of departure for a sophisticated understanding of sustainable development and social sustainability. Redclift shows how complex ecosystems, like tropical rainforests, achieve ecosustainability or homeostatic balance through protection from rapid change and "through shifts of energy flows away from production and towards the maintenance of the system itself" $(1987,18)$. By contrast, Redclift notes, human settlements typically seek to stall such ecosystems in early stages of ecological succession, where the yield of products is high, but where the stabilizing elements of organic matter and biomass fail to accumulate. High production within these ecosystems, then, comes at a high price: "the cost of confounding nature's strategy of maximum protection or adaptation" (18).

Because we believe targeting sustainable development strategically at the global or national scale all but makes impossible meaningful ecological/social analysis and concerted political action, we ground our concept and strategy for sustainable cities upon that argument that "the city presents itself as the largest unit capable of addressing the many urban architectural, social, economic, political, natural resource, and environmental imbalances besetting the modern world and, simultaneously, the smallest scale at which such problems can be meaningfully resolved in an integrated and holistic fashion" (Yanarella and Levine 1992b, 305).

\section{References}

Arendt, Hannah. 1958. The Human Condition. Garden City, NY: Doubleday Anchor Books.

Bleeker, Julian. 1995. "Urban Crisis: Past, Present, and Virtual." Socialist Review 25: $189-221$.

Bukatman, Scott. 1993. Terminal Identity: The Virtual Subject in Postmodern Science Fiction. Durham: Duke University Press.

Calvino, Italo. 1972. Invisible Cities. New York: Harcourt Brace Jovanovich.

Daly, Herman E., and John B. Cobb Jr. 1989. For the Common Good: Redirecting the Economy Toward Community, the Environment, and a Sustainable Future. Boston: Beacon Press.

Ehrenfeld, David. 1981. The Arrogance of Humanism. New York: Oxford University Press.

Graham, Stephen, and Simon Marvin. 1996. Telecommunications and the City: Elec- tronic Spaces, Urban Places. New York: Routledge.

Levine, Richard S., and Ernest J. Yanarella. 1994. "Don't Pick the Low-Lying Fruit: Sustainability from Pathway to Process." University of Kentucky. Manuscript.

, and Taghi Radmard. 1992. "The Two Step Process for Generating Sustainable Cities." Presented at the Second International Ecological Cities Conference, Adelaide, Australia.

Mitchell, William C. 1995. City of Bits: Space, Place, and the Infobahn. Boston: MIT

Press. (Available online: http://mitpress.mit. edu/e-books/City_of_Bits/.)

Mumford, Lewis. 1961. The City in History. New York: Harcourt Brace Jovanovich.

Poster, Mark. 1995. "Cyberdemocracy: Internet and the Public Sphere" <www.humanities. uci.edu/mposter/writings/democ.html $>$. July 23, 1998
Redclift, Michael. 1987. Sustainable Development: Exploring the Contradictions. New York: Methuen.

Starr, Paul. 1994. "Seductions of Sim: Policy as Simulation Game." American Prospect 17(Spring): 19-29.

United Nations. Brundtland Commission. 1987. Our Common Future. New York: United Nations.

Yanarella, Ernest J., Hugh Bartling, Robert Lancaster, and Christopher Rice. 1997. "Oakland Ecopolis: Plan for a Green Plan." We the People <http://wtp.org/ecopolis. html $>$. July 23, 1998.

- and Richard S. Levine. 1992a. "Does Sustainable Development Lead to Sustainability?" Futures 24(October): 759-74.

— 1992b. "The Sustainable Cities Manifesto: Pretext, Text, and Post-Text." Built Environment 18(4): 301-13. 